\title{
Blackheads in the forearm: a case of nevus comedonicus
}

\author{
Paulo Morais ${ }^{*}, 1$, Lígia Peralta ${ }^{2}$, Fortunato Vieira ${ }^{3}$ \\ ${ }^{1}$ Department of Dermatology, ${ }^{2}$ Department of Pediatrics, Tondela-Viseu Hospital Center, Viseu, \\ Portugal; ${ }^{3}$ Histocit - Laboratório de Anatomia Patológica, Trofa, Portugal
}

\begin{abstract}
Nevus comedonicus (NC) is a hamartoma of pilosebaceous unit, which clinically appears as a group of closely dilated follicular openings with keratin plugs resembling open comedones. It is considered as a rare subtype of epidermal nevus. NC usually occurs as an isolated finding but may be associated with extracutaneous anomalies in the context of nevus comedonicus syndrome. We herewith describe a 12 year-old girl with this particular class of epidermal nevus.
\end{abstract}

Keywords: nevus comedonicus, comedo nevus, epidermal nevus.

\section{Introduction}

Nevus comedonicus, also known as comedo nevus or follicular nevus, is a rare subtype of epidermal nevus, first described in 1895 by Kofmann [1]. It is thought to be caused by a defect in the development of the hair follicle.

\section{Case report}

An otherwise healthy 12 year-old girl was referred to the pediatric dermatology clinic due to multiple asymptomatic black pits over the anterior surface of her right forearm, which were present since birth and spread gradually in the last 2 years (Figure 1).

Skin examination revealed multiple grouped pits filled with brownish to dark-black plugs, 1-2 $\mathrm{mm}$ in diameter, arranged in a linear interrupted configuration along the volar aspect of the forearm.

Received: July 2016; Accepted after review: August 2016; Published: September 2016.

*Corresponding author: Paulo Morais, Tondela-Viseu Hospital Center, Av. Rei Dom Duarte, 3504-509 Viseu, Portugal; phone: +351.232420500 .

E-mail: paulomoraiscardoso@gmail.com
Skin examination revealed multiple grouped pits filled with brownish to dark-black plugs, 1-2 $\mathrm{mm}$ in diameter, arranged in a linear interrupted configuration along the volar aspect of the forearm.

Some of the pits presented a hyperpigmented halo and overall the lesions had a comedo-like appearance.

The remainder of the physical examination was normal. There was no history suggestive of skeletal, ocular or other systemic involvement, and family history was unremarkable.

General laboratory findings were within normal limits. Punch biopsy taken from a lesion was sent to histopathological examination, which revealed deep, wide invagination of acanthotic epidermis, filled with concentric lamellae of keratin but absence of hair shafts (Figure 2). These histopathological features were consistent with the diagnosis of nevus comedonicus. To exclude nevus comedonicus syndrome further investigation was carried out, including upper limbs, chest and spine X-rays, as well as ophthalmological and otological evaluation, but no anomalies were found. 

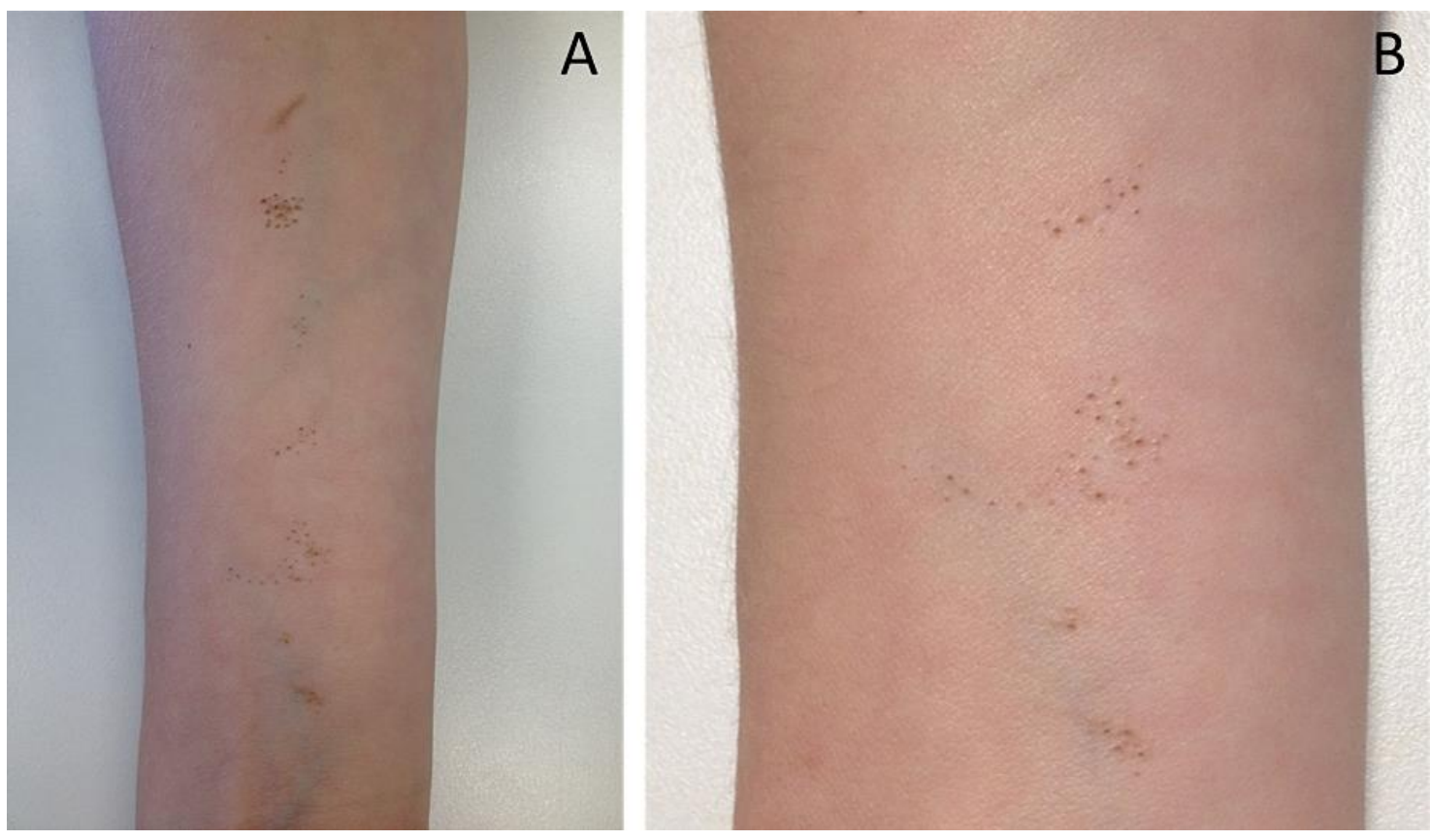

Fig. 1. Clinical appearance of our patient. Note closely arranged, dilated follicular openings with keratinous plugs resembling classic comedones distributed along the volar surface of the left forearm $(A)$; close-up view of the lesion (B).

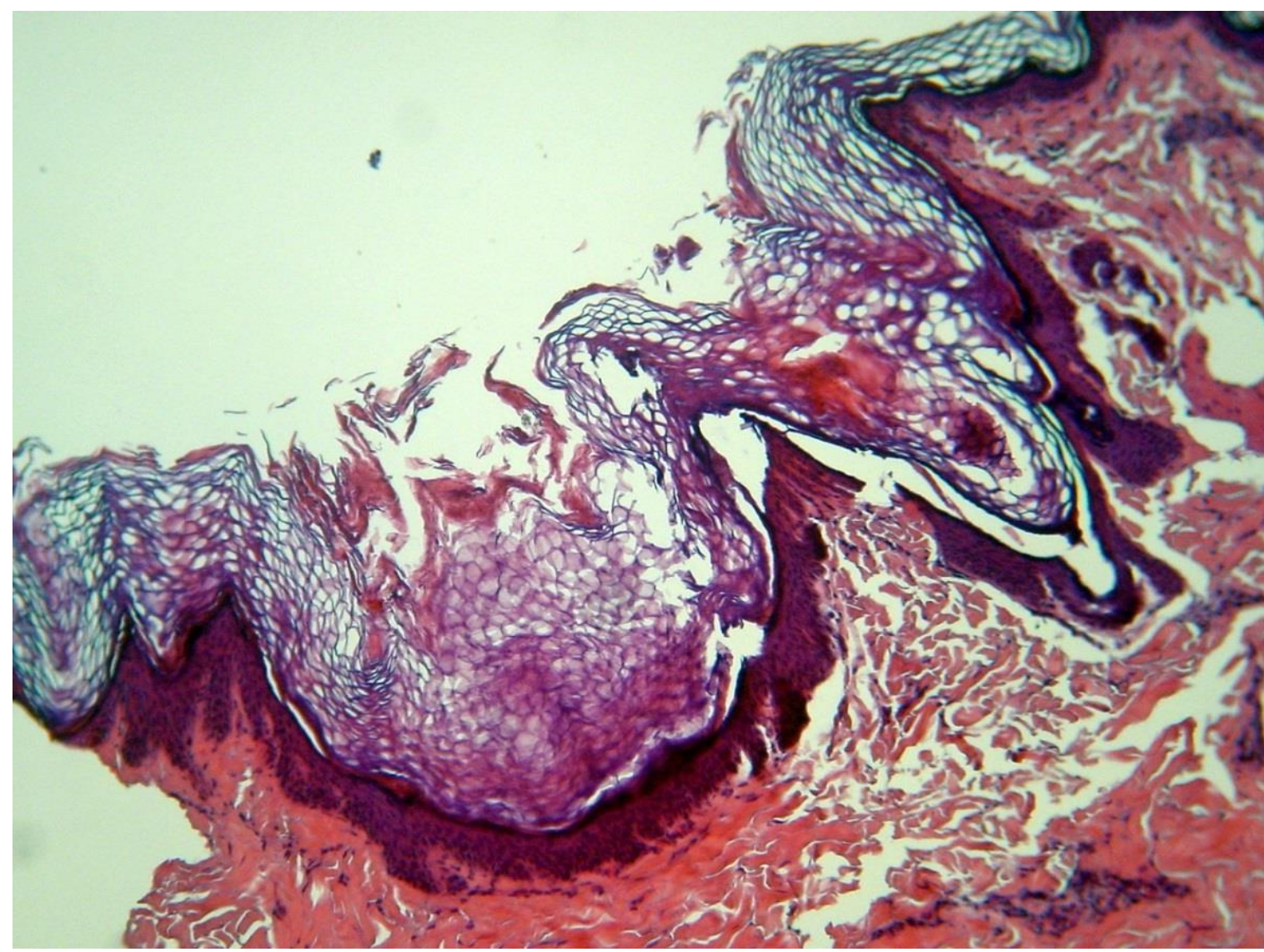

Fig. 2. Histopathology revealing large follicles containing lamellated keratin, but devoid of hair shafts $(H E, x 100)$ 


\section{Discussions}

NC is a hamartoma of the pilosebaceous unit. Recently, it was demonstrated that NC is marked by loss of follicular differentiation markers, and somatic mutations in NEK9 gene may cause the disorder [2]. The undifferentiated epithelium lining the hair follicles produces keratin that forms a laminated plug.

Clinically, NC is characterized by closely arranged, dilated follicular openings with dark keratinous plugs resembling blackheads (open comedones) [3]. However, contrary to acne comedones the material cannot be easily removed mechanically [4]. Lesions may present with various patterns of distribution, including linear, interrupted, unilateral or bilateral, segmental, or blaschkoid [5]. NC is usually asymptomatic and most commonly affects the face, neck, chest, and upper arms [3]. Lesions are usually present at birth or develop in early childhood and growth is accelerated during puberty. Men and women are equally affected, and there is no racial predisposition [4, 5].

The condition may be complicated by inflammatory and nodulo-cystic acne-like lesions, especially after puberty, scarring or secondary infection. Secondary skin tumors can develop on preexistent NC, which are usually benign, but malignant neoplasias were also reported in this setting $[3,6]$.

NC can be associated with skeletal, ocular, and central nervous system abnormalities in the context of nevus comedonicus syndrome (NCS) [5, 7].

The most common symptoms of this neurocutaneous syndrome include cataracts,

\section{References}

1. Kofmann S. Ein Fall von seltener Lokalisation und Verbreitung von Komedonen. Arch Dermatol Syphilol 1895; 32:177-178.

2. Levinsohn JL, Sugarman JL. Yale Center for Mendelian Genomics, McNiff JM, Antaya RJ, Choate KA. Somatic mutations in NEK9 cause nevus comedonicus. Am J Hum Genet 2016; 98:1030-1037.

3. Tchernev G, Ananiev J, Semkova K, Dourmishev LA, Schönlebe J, Wollina U. scoliosis, fused vertebrae, spina bifida, and delayed mental development $[5,7,8]$.

Segmental basaloid follicular hamartomas may clinically resemble NC [9]. Histopathological differential diagnoses of NC include: trichofolliculoma, dilated pore of Winer, pilar sheath acanthoma, and folliculocystic and collagen comedo hamartoma [3].

There is no specific treatment for NC. Being a benign lesion, it does not require aggressive treatment, except for cosmetic purposes [3]. Treatment options include topical therapy (emollients, keratolytics such as salicylic acid or $12 \%$ ammonium lactate lotion, retinoids, vitamin $D_{3}$ analogues, and corticosteroids for inflammatory lesions), laser treatment (Nd:YAG, Er:YAG, $\mathrm{CO}_{2}$, diode), and surgery (curettage, dermabrasion or excision) $[3,10,11]$.

Oral antibiotics may be necessary for deeper inflammatory lesions and retinoids, although of little sustained benefit, may be an option in widespread systematized inflammatory variants [12].

\section{Conclusions}

Physicians should recognize this entity and be aware of potential association of NC with extracutaneous manifestations and skin tumors.

\section{Conflict of interest}

Authors declare no conflicts of interest.
Nevus comedonicus: an updated review. Dermatol Ther 2013; 3:33-40.

4. Nabai $\mathrm{H}$, Mehregan $\mathrm{AH}$. Nevus comedonicus. Acta Derm Venereol 1973; 53:71-74.

5. Happle R. The group of epidermal nevus syndromes Part I. Well defined phenotypes. J Am Acad Dermatol 2010; 63:1-22.

6. Walling HW, Swick BL. Squamous cell carcinoma arising in nevus comedonicus. Dermatol Surg 2009; 35:144-146. 
7. Yadav P, Mendiratta V, Rana S, Chander R. Nevus comedonicus syndrome. Indian $J$ Dermatol 2015; 60:421.

8. Pavithra S, Pai H, Mallya H, Pai GS. Nevus comedonicus syndrome. Indian J Dermatol 2011; 56:771-772.

9. Happle R, Tinschert S. Segmentally arranged basaloid follicular hamartomas with osseous, dental and cerebral anomalies: a distinct syndrome. Acta Derm Venereol 2008; 88:382387.
10. Deliduka SB, Kwong PC. Treatment of Nevus comedonicus with topical tazarotene and calcipotriene. J Drugs Dermatol 2004; 3:674676.

11. Milburn S, Whallett E, Hancock $K$, Munnoch DA, Stevenson $\mathrm{JH}$. The treatment of naevus comedonicus. Br J Plast Surg 2004; 57:805806.

12. Decherd JW, Mills O, Leyden JJ. Naevus comedonicus - treatment with retinoic acid. $\mathrm{Br}$ J Dermatol 1972; 86:528-529. 